Research Article

\title{
On Fuzzy Fixed Points for Fuzzy Maps with Generalized Weak Property
}

\author{
Marwan Amin Kutbi, ${ }^{1}$ Jamshaid Ahmad, ${ }^{2}$ Akbar Azam, ${ }^{2}$ and Nawab Hussain ${ }^{1}$ \\ ${ }^{1}$ Department of Mathematics, King Abdulaziz University, P.O. Box 80203, Jeddah 21589, Saudi Arabia \\ ${ }^{2}$ Department of Mathematics, COMSATS Institute of Information Technology, Chak Shahzad, Islamabad 44000, Pakistan
}

Correspondence should be addressed to Jamshaid Ahmad; jamshaid_jasim@yahoo.com

Received 9 April 2014; Accepted 24 April 2014; Published 20 May 2014

Academic Editor: Giuseppe Marino

Copyright (C) 2014 Marwan Amin Kutbi et al. This is an open access article distributed under the Creative Commons Attribution License, which permits unrestricted use, distribution, and reproduction in any medium, provided the original work is properly cited.

Let $(X, d)$ be a complex valued metric space and let $S$, $T$ be mappings from $X$ to a set of all fuzzy subsets of $X$. We present sufficient conditions for the existence of a common $\alpha$-fuzzy fixed point of $S$ and $T$. Our results improve and extend certain recent results in literature. Moreover, we discuss an illustrative example to highlight the realized improvements.

\section{Introduction}

In 1981, Heilpern [1] used the concept of fuzzy set to introduce a class of fuzzy mappings, which is a generalization of the set-valued mapping, and proved a fixed point theorem for fuzzy contraction mappings in a metric linear space. It is worth noting that the result announced by Heilpern [1] forms a fuzzy extension of the Banach contraction principle. Subsequently, several other authors have studied existence of fixed points of fuzzy mappings or in fuzzy metric spaces; for example, see the work of Azam et al. [2, 3], Bose et al. [4], Chang et al. [5], Cho and Petrot [6], Hussain et al. [7], Qiu and Shu [8], Rashwan and Ahmed [9], and Zhang [10].

Recently, Azam et al. [11] introduced the concept of complex valued metric space and obtained sufficient conditions for the existence of common fixed points of a pair of mappings satisfying contractive type condition involving rational expressions. For more details on complex valued metric space we refer the reader to [12-17].

In [18], Azam obtained some common fuzzy fixed points for fuzzy mappings under a rational contractive condition on a metric space in connection with the Hausdorff metric on the family of fuzzy sets.

The aim of this paper is to obtain a common $\alpha$-fuzzy fixed point of a pair of fuzzy mappings $S$ and $T$ on a complete complex valued metric space under a generalized rational contractive condition for $\alpha$-level sets. Our results generalize the results proved by Azam et al. $[11,18]$.

\section{Preliminaries}

Let $\mathbb{C}$ be the set of complex numbers and $z_{1}, z_{2} \in \mathbb{C}$. Define a partial order $\preccurlyeq$ on $\mathbb{C}$ as follows:

$$
\begin{aligned}
z_{1} \preccurlyeq z_{2} \quad \text { iff } \operatorname{Re}\left(z_{1}\right) & \leqslant \operatorname{Re}\left(z_{2}\right), \\
\operatorname{Im}\left(z_{1}\right) & \leqslant \operatorname{Im}\left(z_{2}\right) .
\end{aligned}
$$

It follows that

$$
z_{1} \precsim z_{2}
$$

if one of the following conditions is satisfied:

(i) $\operatorname{Re}\left(z_{1}\right)=\operatorname{Re}\left(z_{2}\right), \operatorname{Im}\left(z_{1}\right)<\operatorname{Im}\left(z_{2}\right)$,

(ii) $\operatorname{Re}\left(z_{1}\right)<\operatorname{Re}\left(z_{2}\right), \operatorname{Im}\left(z_{1}\right)=\operatorname{Im}\left(z_{2}\right)$,

(iii) $\operatorname{Re}\left(z_{1}\right)<\operatorname{Re}\left(z_{2}\right), \operatorname{Im}\left(z_{1}\right)<\operatorname{Im}\left(z_{2}\right)$,

(iv) $\operatorname{Re}\left(z_{1}\right)=\operatorname{Re}\left(z_{2}\right), \operatorname{Im}\left(z_{1}\right)=\operatorname{Im}\left(z_{2}\right)$. 
In particular, we will write $z_{1} \preccurlyeq z_{2}$ if $z_{1} \neq z_{2}$ and one of (i), (ii), and (iii) is satisfied and we will write $z_{1} \prec z_{2}$ if only (iii) is satisfied. Note that

$$
\begin{gathered}
0 \preceq z_{1} \precsim z_{2} \Longrightarrow\left|z_{1}\right|<\left|z_{2}\right|, \\
z_{1} \preceq z_{2}, z_{2} \prec z_{3} \Longrightarrow z_{1} \prec z_{3} .
\end{gathered}
$$

Definition 1. Let $X$ be a nonempty set. Suppose that the mapping

$$
d: X \times X \longrightarrow \mathbb{C}
$$

satisfies

$$
\begin{aligned}
& \text { (1) } 0 \precsim d(x, y) \text {, for all } x, y \in X \text { and } d(x, y)=0 \text { if and } \\
& \text { only if } x=y \text {; } \\
& \text { (2) } d(x, y)=d(y, x) \text { for all } x, y \in X \text {; } \\
& \text { (3) } d(x, y) \precsim d(x, z)+d(z, y) \text {, for all } x, y, z \in X \text {. }
\end{aligned}
$$

Then $d$ is called a complex valued metric on $X$, and $(X, d)$ is called a complex valued metric space. A point $x \in X$ is called interior point of a set $A \subseteq X$ whenever there exists $0 \prec r \in \mathbb{C}$ such that

$$
B(x, r)=\{y \in X: d(x, y) \prec r\} \subseteq A .
$$

A point $x \in X$ is called a limit point of $A$ whenever, for every $0 \prec r \in \mathbb{C}$,

$$
B(x, r) \cap(A \backslash\{x\}) \neq \phi .
$$

$A$ is called open whenever each element of $A$ is an interior point of $A$. Moreover, a subset $B \subseteq X$ is called closed whenever each limit point of $B$ belongs to $B$. The family

$$
F=\{B(x, r): x \in X, 0 \prec r\}
$$

is a subbasis for a Hausdorff topology $\tau$ on $X$.

Let $x_{n}$ be a sequence in $X$ and $x \in X$. If for every $c \in \mathbb{C}$ with $0 \prec c$ there is $n_{0} \in \mathbb{N}$ such that, for all $n>n_{0}, d\left(x_{n}, x\right) \prec c$, then $\left\{x_{n}\right\}$ is said to be convergent, $\left\{x_{n}\right\}$ converges to $x$, and $x$ is the limit point of $\left\{x_{n}\right\}$. We denote this by $\lim _{n \rightarrow \infty} x_{n}=x$, or $x_{n} \rightarrow x$, as $n \rightarrow \infty$. If for every $c \in \mathbb{C}$ with $0 \prec c$ there is $n_{0} \in \mathbb{N}$ such that, for all $n>n_{0}, d\left(x_{n}, x_{n+m}\right) \prec c$, where $m \in \mathbb{N}$, then $\left\{x_{n}\right\}$ is called a Cauchy sequence in $(X, d)$. If every Cauchy sequence is convergent in $(X, d)$, then $(X, d)$ is called a complete complex valued metric space. We require the following lemmas.

Lemma 2 (see [11]). Let $(X, d)$ be a complex valued metric space and let $\left\{x_{n}\right\}$ be a sequence in $X$. Then $\left\{x_{n}\right\}$ converges to $x$ if and only if $\left|d\left(x_{n}, x\right)\right| \rightarrow 0$ as $n \rightarrow \infty$.

Lemma 3 (see [11]). Let $(X, d)$ be a complex valued metric space and let $\left\{x_{n}\right\}$ be a sequence in $X$. Then $\left\{x_{n}\right\}$ is a Cauchy sequence if and only if $\left|d\left(x_{n}, x_{n+m}\right)\right| \rightarrow 0$ as $n \rightarrow \infty$, where $m \in \mathbb{N}$.

A fuzzy set in $X$ is a function with domain $X$ and values in $[0,1] ; I^{X}$ is the collection of all fuzzy sets in $X$. If $A$ is a fuzzy set and $x \in X$, then the function values $A(x)$ are called the grade of membership of $x$ in $A$. The $\alpha$-level set of $A$ is denoted by $[A]_{\alpha}$ and is defined as follows:

$$
\begin{gathered}
{[A]_{\alpha}=\{x: A(x) \geq \alpha\} \quad \text { if } \alpha \in(0,1],} \\
{[A]_{0}=\overline{\{x: A(x)>0\}} .}
\end{gathered}
$$

Here $\bar{B}$ denotes the closure of the set $B$. Let $\mathscr{F}(X)$ be the collection of all fuzzy sets in a metric space $X$. For $A, B \in$ $\mathscr{F}(X), A \subset B$ means $A(x) \leq B(x)$ for each $x \in X$. We denote the fuzzy set $\chi_{\{x\}}$ by $\{x\}$ unless and until it is stated, where $\chi_{\{A\}}$ is the characteristic function of the crisp set $A$. A fuzzy set $A$ in a metric linear space $V$ is said to be an approximate quantity if and only if $[A]_{\alpha}$ is compact and convex in $V$ for each $\alpha \in[0,1]$ and $\sup _{x \in V} A(x)=1$. The collection of all approximate quantities in $V$ is denoted by $W(V)$.

Definition 4. Let $X$ be a nonempty set and let $(Y, d)$ be a complex valued metric space. A mapping $T$ is called fuzzy mapping if $T$ is a mapping from $X$ into $(Y)$. A fuzzy mapping $T$ is a fuzzy subset on $X \times Y$ with membership function $T(x)(y)$. The function $T(x)(y)$ is the grade of membership of $y$ in $T(x)$.

Definition 5. Let $(X, d)$ be a complex valued metric space and let $S, T$ be fuzzy mappings from $X$ into $(X)$. A point $z \in X$ is called a fuzzy fixed point of $T$ if $z \in[T z]_{\alpha}$, for some $\alpha \in$ $[0,1]$. The point $z \in X$ is called a common fuzzy fixed point of $S$ and $T$ if $z \in[S z]_{\alpha} \cap[T z]_{\alpha}$ for some $\alpha \in[0,1]$. When $\alpha=1, z$ is called a common fixed point of fuzzy mappings.

\section{Main Result}

Let $(X, d)$ be a complex valued metric space. We denote the family of all nonempty, closed and bounded subsets of a complex valued metric space $X$ by $\mathfrak{E} \mathfrak{B}(X)$.

From now on, we denote $s\left(z_{1}\right)=\left\{z_{2} \in \mathbb{C}: z_{1} \preceq z_{2}\right\}$ for $z_{1} \in \mathbb{C}$ and $s(a, B)=\cup_{b \in B} s(d(a, b))=\cup_{b \in B}\{z \in \mathbb{C}: d(a, b) \preceq$ $z\}$ for $a \in X$ and $B \in \mathfrak{C} \mathfrak{B}(X)$.

For $A, B \in \mathfrak{C} \mathfrak{B}(X)$, we denote

$$
s(A, B)=\left(\bigcap_{a \in A} s(a, B)\right) \cap\left(\bigcap_{b \in B} s(b, A)\right) .
$$

Lemma 6. Let $(X, d)$ be a complex valued metric space.

(i) Let $p, q \in \mathbb{C}$. If $p \preceq q$, then $s(q) \subset s(p)$

(ii) Let $x \in X$ and $A \in N(X)$. If $\theta \in s(x, A)$, then $x \in A$.

(iii) Let $q \in \mathbb{C}$ and let $A, B \in \mathfrak{C B}(X)$ and $a \in A$. If $q \in$ $s(A, B)$, then $q \in s(a, B)$ for all $a \in A$ or $q \in s(A, b)$ for all $b \in B$.

Remark 7. If $(X, d)$ is a metric space, for $A, B \in$ $\mathfrak{E B}(X), H(A, B)=\inf s(A, B)$ is the Hausdorff distance induced by the metric $d$.

Let $(X, d)$ be a complex valued metric space and $\mathfrak{c}(X)$ be a collection of nonempty closed subsets of $X$. Let 
$T: X \rightarrow \mathfrak{C} \mathfrak{B}(X)$ be a multivalued map. For $x \in X$ and $A \in \mathbb{E} \mathfrak{B}(X)$, define

$$
W_{x}(A)=\{d(x, a): a \in A\} .
$$

Thus for $x, y \in X$

$$
W_{x}(T y)=\{d(x, u): u \in T y\} .
$$

Definition 8. Let $(X, d)$ be a complex valued metric space. A subset $A$ of $X$ is called bounded from below if there exists some $z \in X$, such that $z \preceq a$ for all $a \in A$.

Definition 9. Let $(X, d)$ be a complex valued metric space. A multivalued mapping $F: X \rightarrow 2^{\mathbb{C}}$ is called bounded from below if for each $x \in X$ there exists $z_{x} \in \mathbb{C}$ such that

$$
z_{x} \preceq u,
$$

for all $u \in F x$.

Definition 10. Let $(X, d)$ be a complex valued metric space. The fuzzy mapping $T: X \rightarrow \mathscr{F}(X)$ is said to have lower bound property (l.b property) on $(X, d)$, if, for any $x \in X$ associated with some $\alpha \in(0,1]$, the multivalued mapping $F_{x}$ : $X \rightarrow 2^{\mathbb{C}}$ defined by

$$
F_{x}(y)=W_{x}\left([T y]_{\alpha}\right)
$$

is bounded from below. That is, for $x, y \in X$ there exists an element $l_{x}\left([T y]_{\alpha}\right) \in \mathbb{C}$ such that

$$
l_{x}\left([T y]_{\alpha}\right) \preceq u,
$$

for all $u \in W_{x}\left([T y]_{\alpha}\right)$, where $l_{x}\left([T y]_{\alpha}\right)$ is called lower bound of $T$ associated with $(x, y)$.

Definition 11. Let $(X, d)$ be a complex valued metric space. The fuzzy mapping $T: X \rightarrow \mathscr{F}(X)$ is said to have greatest lower bound property (g.l.b property) on $(X, d)$, if for any $x \in X$ and any $\alpha \in(0,1]$, greatest lower bound of $W_{x}\left([T y]_{\alpha}\right)$ exists in $\mathbb{C}$ for all $y \in X$. One denotes $d\left(x,[T y]_{\alpha}\right)$ by the g.l.b of $W_{x}\left([T y]_{\alpha}\right)$. That is,

$$
d\left(x,[T y]_{\alpha}\right)=\inf \left\{d(x, u): u \in[T y]_{\alpha}\right\} .
$$

\subsection{Banach Type Fuzzy Fixed Point Result}

Theorem 12. Let $(X, d)$ be a complete complex valued metric space and let $S, T$ be fuzzy mappings from $X$ into $\mathscr{F}(X)$. Assume that there exists some $\alpha \in(0,1]$, such that, for each $x \in X,[S x]_{\alpha}$ and $[T x]_{\alpha}$ are nonempty closed bounded subsets of $X$; greatest lower bound of $W_{x}\left([T y]_{\alpha}\right), W_{x}\left([S y]_{\alpha}\right)$ exists in $\mathbb{C}$ for all $y \in X$ and

$$
\begin{aligned}
& \zeta d(x, y) \\
& +\frac{\kappa d\left(x,[S x]_{\alpha}\right) d\left(y,[T y]_{\alpha}\right)+\varsigma d\left(y,[S x]_{\alpha}\right) d\left(x,[T y]_{\alpha}\right)}{1+d(x, y)} \\
& \quad \in s\left([S x]_{\alpha},[T y]_{\alpha}\right),
\end{aligned}
$$

for all $x, y \in X$, where $\zeta, \kappa, \varsigma$ are nonnegative real numbers with $\zeta+\kappa+\varsigma<1$. Then there exists some $u \in[S u]_{\alpha} \cap[\mathrm{Tu}]_{\alpha}$.
Proof. Let $x_{0}$ be an arbitrary point in $X$. By assumption, we can find $x_{1} \in\left[S x_{0}\right]_{\alpha}$. So, we have

$$
\begin{aligned}
\zeta d\left(x_{0}, x_{1}\right)+ & \left(\left(\kappa d\left(x_{0},\left[S x_{0}\right]_{\alpha}\right) d\left(x_{1},\left[T x_{1}\right]_{\alpha}\right)\right.\right. \\
& \left.+\varsigma d\left(x_{1},\left[S x_{0}\right]_{\alpha}\right) d\left(x_{0},\left[T x_{1}\right]_{\alpha}\right)\right) \\
& \left.\times\left(1+d\left(x_{0}, x_{1}\right)\right)^{-1}\right) \in s\left(\left[S x_{0}\right]_{\alpha},\left[T x_{1}\right]_{\alpha}\right) .
\end{aligned}
$$

By Lemma 6(iii), we have

$$
\begin{aligned}
\zeta d\left(x_{0}, x_{1}\right)+ & \left(\left(\kappa d\left(x_{0},\left[S x_{0}\right]_{\alpha}\right) d\left(x_{1},\left[T x_{1}\right]_{\alpha}\right)\right.\right. \\
& \left.+\varsigma d\left(x_{1},\left[S x_{0}\right]_{\alpha}\right) d\left(x_{0},\left[T x_{1}\right]_{\alpha}\right)\right) \\
& \left.\times\left(1+d\left(x_{0}, x_{1}\right)\right)^{-1}\right) \in s\left(x_{1},\left[T x_{1}\right]_{\alpha}\right) .
\end{aligned}
$$

By definition there exists some $x_{2} \in\left[T x_{1}\right]_{\alpha}$, such that

$$
\begin{aligned}
\zeta d\left(x_{0}, x_{1}\right)+ & \left(\left(\kappa d\left(x_{0},\left[S x_{0}\right]_{\alpha}\right) d\left(x_{1},\left[T x_{1}\right]_{\alpha}\right)\right.\right. \\
& \left.+\varsigma d\left(x_{1},\left[S x_{0}\right]_{\alpha}\right) d\left(x_{0},\left[T x_{1}\right]_{\alpha}\right)\right) \\
& \left.\times\left(1+d\left(x_{0}, x_{1}\right)\right)^{-1}\right) \in s\left(d\left(x_{1}, x_{2}\right)\right) .
\end{aligned}
$$

That is,

$$
\begin{aligned}
d\left(x_{1}, x_{2}\right) \leq \zeta d\left(x_{0}, x_{1}\right)+ & \left(\left(\kappa d\left(x_{0},\left[S x_{0}\right]_{\alpha}\right) d\left(x_{1},\left[T x_{1}\right]_{\alpha}\right)\right.\right. \\
& \left.+\varsigma d\left(x_{1},\left[S x_{0}\right]_{\alpha}\right) d\left(x_{0},\left[T x_{1}\right]_{\alpha}\right)\right) \\
& \left.\times\left(1+d\left(x_{0}, x_{1}\right)\right)^{-1}\right) .
\end{aligned}
$$

By the meaning of $W_{x}\left([T y]_{\alpha}\right)$ and $W_{x}\left([S y]_{\alpha}\right)$ for $x, y \in X$, we get

$$
\begin{aligned}
d\left(x_{1}, x_{2}\right) \leq & \zeta d\left(x_{0}, x_{1}\right) \\
& +\frac{\kappa d\left(x_{0}, x_{1}\right) d\left(x_{1}, x_{2}\right)+\varsigma d\left(x_{1}, x_{1}\right) d\left(x_{0}, x_{2}\right)}{1+d\left(x_{0}, x_{1}\right)} \\
= & \zeta d\left(x_{0}, x_{1}\right)+\frac{\kappa d\left(x_{0}, x_{1}\right) d\left(x_{1}, x_{2}\right)}{1+d\left(x_{0}, x_{1}\right)},
\end{aligned}
$$

which implies that

$$
\begin{aligned}
&\left|d\left(x_{1}, x_{2}\right)\right| \leq \zeta\left|d\left(x_{0}, x_{1}\right)\right|+\frac{\kappa\left|d\left(x_{0}, x_{1}\right)\right|\left|d\left(x_{1}, x_{2}\right)\right|}{\left|1+d\left(x_{0}, x_{1}\right)\right|} \\
&= \zeta\left|d\left(x_{0}, x_{1}\right)\right|+\kappa\left|d\left(x_{1}, x_{2}\right)\right|\left|\frac{d\left(x_{0}, x_{1}\right)}{1+d\left(x_{0}, x_{1}\right)}\right|, \\
&\left|d\left(x_{1}, x_{2}\right)\right| \leq \zeta\left|d\left(x_{0}, x_{1}\right)\right|+\kappa\left|d\left(x_{1}, x_{2}\right)\right|, \\
&(1-\kappa)\left|d\left(x_{1}, x_{2}\right)\right| \leq \zeta\left|d\left(x_{0}, x_{1}\right)\right|,
\end{aligned}
$$


where

$$
h=\frac{\zeta}{1-\kappa}<1
$$

Inductively, we can construct a sequence $\left\{x_{n}\right\}$ in $X$ such that, for $n=0,1,2, \ldots$,

$$
\left|d\left(x_{n}, x_{n+1}\right)\right| \leq h^{n}\left|d\left(x_{0}, x_{1}\right)\right|,
$$

with $h=\zeta /(1-\kappa)<1$, for $x_{2 n+1} \in\left[S x_{2 n}\right]_{\alpha}$ and $x_{2 n+2} \in$ $\left[T x_{2 n+1}\right]_{\alpha}$.

Now for $m>n$, we get

$$
\begin{aligned}
\left|d\left(x_{n}, x_{m}\right)\right| \leq & \left|d\left(x_{n}, x_{n+1}\right)\right| \\
& +\left|d\left(x_{n+1}, x_{n+2}\right)\right|+\cdots+\left|d\left(x_{m-1}, x_{m}\right)\right| \\
\leq & {\left[h^{n}+h^{n+1}+\cdots+h^{m-1}\right]\left|d\left(x_{0}, x_{1}\right)\right| } \\
\leq & {\left[\frac{h^{n}}{1-h}\right]\left|d\left(x_{0}, x_{1}\right)\right|, }
\end{aligned}
$$

and so

$$
\left|d\left(x_{n}, x_{m}\right)\right| \leq \frac{h^{n}}{1-h}\left|d\left(x_{0}, x_{1}\right)\right| \longrightarrow 0, \quad \text { as } m, n \rightarrow \infty .
$$

This implies that $\left\{x_{n}\right\}$ is a Cauchy sequence in $X$. Since $X$ is complete, so there exists $u \in X$ such that $x_{n} \rightarrow u$ as $n \rightarrow$ $\infty$. We now show that $u \in[T u]_{\alpha}$ and $u \in[S u]_{\alpha}$. From (16), we have

$$
\begin{aligned}
\zeta d\left(x_{2 k}, u\right)+( & \left(\kappa d\left(x_{2 k},\left[S x_{2 k}\right]_{\alpha}\right) d\left(u,[T u]_{\alpha}\right)\right. \\
& \left.+\varsigma d\left(u,\left[S x_{2 k}\right]_{\alpha}\right) d\left(x_{2 k},[T u]_{\alpha}\right)\right) \\
& \left.\times\left(1+d\left(x_{2 k}, u\right)\right)^{-1}\right) \in s\left(\left[S x_{2 k}\right]_{\alpha},[T u]_{\alpha}\right) .
\end{aligned}
$$

By Lemma 6(iii), we have

$$
\begin{aligned}
\zeta d\left(x_{2 k}, u\right)+( & \left(\kappa d\left(x_{2 k},\left[S x_{2 k}\right]_{\alpha}\right) d\left(u,[T u]_{\alpha}\right)\right. \\
& \left.+\varsigma d\left(u,\left[S x_{2 k}\right]_{\alpha}\right) d\left(x_{2 k},[T u]_{\alpha}\right)\right) \\
& \left.\times\left(1+d\left(x_{2 k}, u\right)\right)^{-1}\right) \in s\left(x_{2 k+1},[T u]_{\alpha}\right) .
\end{aligned}
$$

By definition there exists some $u_{k} \in[T u]_{\alpha}$ such that

$$
\begin{aligned}
\zeta d\left(x_{2 k}, u\right)+( & \left(\kappa d\left(x_{2 k},\left[S x_{2 k}\right]_{\alpha}\right) d\left(u,[T u]_{\alpha}\right)\right. \\
& \left.+\varsigma d\left(u,\left[S x_{2 k}\right]_{\alpha}\right) d\left(x_{2 k},[T u]_{\alpha}\right)\right) \\
& \left.\times\left(1+d\left(x_{2 k}, u\right)\right)^{-1}\right) \in s\left(d\left(x_{2 k+1}, u_{k}\right)\right) .
\end{aligned}
$$

That is,

$$
\begin{aligned}
d\left(x_{2 k+1}, u_{k}\right) \preceq \zeta d\left(x_{2 k}, u\right)+ & \left(\left(\kappa d\left(x_{2 k},\left[S x_{2 k}\right]_{\alpha}\right) d\left(u,[T u]_{\alpha}\right)\right.\right. \\
+ & \left.\varsigma d\left(u,\left[S x_{2 k}\right]_{\alpha}\right) d\left(x_{2 k},[T u]_{\alpha}\right)\right) \\
& \left.\times\left(1+d\left(x_{2 k}, u\right)\right)^{-1}\right) .
\end{aligned}
$$

By the meaning of $W_{x}\left([T y]_{\alpha}\right)$ and $W_{x}\left([S y]_{\alpha}\right)$ for $x, y \in X$, we get

$$
\begin{aligned}
& d\left(x_{2 k+1}, u_{k}\right) \preceq \zeta d\left(x_{2 k}, u\right) \\
& \quad+\frac{\kappa d\left(x_{2 k}, x_{2 k+1}\right) d\left(u, u_{k}\right)+\varsigma d\left(u, x_{2 k+1}\right) d\left(x_{2 k}, u_{k}\right)}{1+d\left(x_{2} k_{u}\right)}
\end{aligned}
$$

Since by triangle inequality, we get

$$
d\left(u, u_{k}\right) \preceq d\left(u, x_{2 k+1}\right)+d\left(x_{2 k+1}, u_{k}\right)
$$

So using (31) in (32), we get

$$
\begin{aligned}
& d\left(u, u_{k}\right) \preceq d\left(u, x_{2 k+1}\right)+\zeta d\left(u, x_{2 k+1}\right) \\
& +\frac{\kappa d\left(x_{2 k}, x_{2 k+1}\right) d\left(u, u_{k}\right)+\varsigma d\left(u, x_{2 k+1}\right) d\left(x_{2 k}, u_{k}\right)}{1+d\left(x_{2 k}, u\right)}, \\
& \quad+d\left(u, u_{k}\right)|\leq| d\left(u, x_{2 k+1}\right)|+\zeta| d\left(u, x_{2 k+1}\right) \mid \\
& +\frac{\kappa\left|d\left(x_{2 k}, x_{2 k+1}\right)\right|\left|d\left(u, u_{k}\right)\right|+\varsigma\left|d\left(u, x_{2 k+1}\right)\right|\left|d\left(x_{2 k}, u_{k}\right)\right|}{\left|1+d\left(x_{2 k}, u\right)\right|} .
\end{aligned}
$$

Taking the limit as $k \rightarrow \infty$, we get $\mid d\left(u, u_{k} \mid \rightarrow 0\right.$ as $k \rightarrow$ $\infty$. By Lemma 2 [11], we have $u_{k} \rightarrow u$ as $k \rightarrow \infty$. Since $[T u]_{\alpha}$ is closed, so $u \in[T u]_{\alpha}$. Similarly, it follows that $u \in$ $[S u]_{\alpha}$. Thus $S$ and $T$ have a common fuzzy fixed point.

By setting $\varsigma=0$ in Theorem 12, we get the following corollary.

Corollary 13. Let $(X, d)$ be a complete complex valued metric space and let $S, T$ be fuzzy mappings from $X$ into $\mathscr{F}(X)$. Assume that there exists some $\alpha \in(0,1]$, such that, for each $x \in X,[S x]_{\alpha}$ and $[T x]_{\alpha}$ are nonempty closed bounded subsets of $X$; greatest lower bound of $W_{x}\left([T y]_{\alpha}\right), W_{x}\left([S y]_{\alpha}\right)$ exists in $\mathbb{C}$ for all $y \in X$ and

$$
\zeta d(x, y)+\frac{\kappa d\left(x,[S x]_{\alpha}\right) d\left(y,[T y]_{\alpha}\right)}{1+d(x, y)} \in s\left([S x]_{\alpha},[T y]_{\alpha}\right)
$$

for all $x, y \in X$, where $\zeta$ and $\kappa$ are nonnegative real numbers with $\zeta+\kappa<1$. Then there exists some $u \in[S u]_{\alpha} \cap[\mathrm{Tu}]_{\alpha}$.

By setting $S=T$ in Theorem 12 , we get the following corollary.

Corollary 14. Let $(X, d)$ be a complete complex valued metric space and let $T$ be fuzzy mapping from $X$ into $\mathscr{F}(X)$. Assume that there exists some $\alpha \in(0,1]$, such that, for each $x \in X,[T x]_{\alpha}$ is nonempty closed bounded subset of $X$; 
greatest lower bound of $W_{x}\left([T y]_{\alpha}\right)$ exists in $\mathbb{C}$ for all $y \in$ $X$ and

$$
\begin{aligned}
& \zeta d(x, y) \\
& +\frac{\kappa d\left(x,[T x]_{\alpha}\right) d\left(y,[T y]_{\alpha}\right)+\varsigma d\left(y,[T x]_{\alpha}\right) d\left(x,[T y]_{\alpha}\right)}{1+d(x, y)} \\
& \quad \in s\left([T x]_{\alpha},[T y]_{\alpha}\right),
\end{aligned}
$$

for all $x, y \in X$, where $\zeta, \kappa$, and $\varsigma$ are nonnegative real numbers with $\zeta+\kappa+\varsigma<1$. Then there exists some $u \in[T u]_{\alpha}$.

By Definition 11, one can have the following corollaries easily from Theorem 12 .

Corollary 15. Let $(X, d)$ be a complete complex valued metric space and let $S, T$ be fuzzy mappings from $X$ into $\mathscr{F}(X)$ with g.l.b property such that, for each $x, y \in X$ and $\alpha \in(0,1]$ and $[S x]_{\alpha},[T y]_{\alpha}$ are nonempty closed bounded subsets of $X$ and

$$
\begin{aligned}
& \zeta d(x, y) \\
& +\frac{\kappa d\left(x,[S x]_{\alpha}\right) d\left(y,[T y]_{\alpha}\right)+\varsigma d\left(y,[S x]_{\alpha}\right) d\left(x,[T y]_{\alpha}\right)}{1+d(x, y)} \\
& \quad \in s\left([S x]_{\alpha},[T y]_{\alpha}\right),
\end{aligned}
$$

for all $x, y \in X$, and $\zeta, \kappa$, and $\varsigma$ are nonnegative real numbers with $\zeta+\kappa+\varsigma<1$. Then there exists some $u \in[S u]_{\alpha} \cap[\mathrm{Tu}]_{\alpha}$.

Corollary 16. Let $(X, d)$ be a complete complex valued metric space and let $S, T$ be fuzzy mappings from $X$ into $\mathscr{F}(X)$ with g.l.b property such that, for each $x, y \in X$ and $\alpha \in(0,1]$ and $[S x]_{\alpha},[T y]_{\alpha}$ are nonempty closed bounded subsets of $X$ and

$$
\zeta d(x, y)+\frac{\kappa d\left(x,[S x]_{\alpha}\right) d\left(y,[T y]_{\alpha}\right)}{1+d(x, y)} \in s\left([S x]_{\alpha},[T y]_{\alpha}\right)
$$

for all $x, y \in X$, and $\zeta$ and $\kappa$ are nonnegative real numbers with $\zeta+\kappa<1$. Then there exists some $u \in[S u]_{\alpha} \cap[\mathrm{Tu}]_{\alpha}$.

Corollary 17. Let $(X, d)$ be a complete complex valued metric space and let $T$ be fuzzy mapping from $X$ into $\mathscr{F}(X)$ with g.l.b property such that, for each $x, y \in X$ and $\alpha \in(0,1],[T y]_{\alpha}$ is nonempty closed bounded subset of $X$ and

$$
\begin{aligned}
& \zeta d(x, y) \\
& \quad+\frac{\kappa d\left(x,[T x]_{\alpha}\right) d\left(y,[T y]_{\alpha}\right)+\varsigma d\left(y,[T x]_{\alpha}\right) d\left(x,[T y]_{\alpha}\right)}{1+d(x, y)} \\
& \quad \in s\left([T x]_{\alpha},[T y]_{\alpha}\right),
\end{aligned}
$$

for all $x, y \in X$, and $\zeta, \kappa$, and $\varsigma$ are nonnegative real numbers with $\zeta+\kappa+\varsigma<1$. Then there exists some $u \in[T u]_{\alpha}$.
Corollary 18 (see [19]). Let $(X, d)$ be a complete complex valued metric space and let $F, G: X \rightarrow C B(X)$ be multivalued mappings with g.l.b property such that

$$
\begin{aligned}
& \zeta d(x, y) \\
& +\frac{\kappa d(x, F x) d(y, G y)+\varsigma d(y, F x) d(x, G y)}{1+d(x, y)} \\
& \quad \in s(F x, G y),
\end{aligned}
$$

for all $x, y \in X$, where $\zeta, \kappa$, and $\varsigma$ are nonnegative real numbers with $\zeta+\kappa+\varsigma<1$. Then there exists some $u \in F u \cap T u$.

Proof. Consider a pair of fuzzy mappings $S, T: X \rightarrow \mathscr{F}(X)$ defined by

$$
\begin{aligned}
& S(x)(t)= \begin{cases}\alpha, & t \in F x \\
0, & t \notin F x,\end{cases} \\
& T(x)(t)= \begin{cases}\alpha, & t \in G x \\
0, & t \notin G x,\end{cases}
\end{aligned}
$$

where $\alpha \in(0,1]$. Then

$$
[S x]_{\alpha}=\{t: S(x)(t) \geq \alpha\}=F x, \quad[T x]_{\alpha}=G x .
$$

Thus, Theorem 12 can be applied to obtain $u \in X$ such that

$$
u \in[S u]_{\alpha} \cap[T u]_{\alpha}=F u \cap G u .
$$

\subsection{Kannan Type Fuzzy Fixed Point Result}

Theorem 19. Let $(X, d)$ be a complete complex valued metric space and let $S, T$ be fuzzy mappings from $X$ into $\mathscr{F}(X)$. Assume that there exists some $\alpha \in(0,1]$, such that, for each $x \in X,[S x]_{\alpha}$ and $[T x]_{\alpha}$ are nonempty closed bounded subsets of $X$; greatest lower bound of $W_{x}\left([T y]_{\alpha}\right), W_{x}\left([S y]_{\alpha}\right)$ exists in $\mathbb{C}$ for all $y \in X$ and

$$
\begin{gathered}
\beta d\left(x,[S x]_{\alpha}\right)+\gamma d\left(y,[T y]_{\alpha}\right) \\
+\eta \frac{d\left(x,[S x]_{\alpha}\right) d\left(y,[T y]_{\alpha}\right)}{1+d(x, y)} \\
\in s\left([S x]_{\alpha},[T y]_{\alpha}\right),
\end{gathered}
$$

for all $x, y \in X$ and nonnegative real numbers $\beta, \gamma$, and $\eta$ with $\beta+\gamma+\eta<1$. Then there exists some $v \in[S v]_{\alpha} \cap[T v]_{\alpha}$.

Proof. Let $x_{0}$ be an arbitrary point in $X$. By assumption, we can find $x_{1} \in\left[S x_{0}\right]_{\alpha}$. So, we have

$$
\begin{aligned}
& \beta d\left(x_{0},\left[S x_{0}\right]_{\alpha}\right)+\gamma d\left(x_{1},\left[T x_{1}\right]_{\alpha}\right) \\
& +\eta \frac{d\left(x_{0},\left[S x_{0}\right]_{\alpha}\right) d\left(x_{1},\left[T x_{1}\right]_{\alpha}\right)}{1+d\left(x_{0}, x_{1}\right)} \\
& \quad \in s\left(\left[S x_{0}\right]_{\alpha},\left[T x_{1}\right]_{\alpha}\right) .
\end{aligned}
$$


By Lemma 6(iii), we have

$$
\begin{aligned}
& \beta d\left(x_{0},\left[S x_{0}\right]_{\alpha}\right)+\gamma d\left(x_{1},\left[T x_{1}\right]_{\alpha}\right) \\
& +\eta \frac{d\left(x_{0},\left[S x_{0}\right]_{\alpha}\right) d\left(x_{1},\left[T x_{1}\right]_{\alpha}\right)}{1+d\left(x_{0}, x_{1}\right)} \\
& \quad \in s\left(x_{1},\left[T x_{1}\right]_{\alpha}\right) .
\end{aligned}
$$

By definition there exists some $x_{2} \in\left[T x_{1}\right]_{\alpha}$, such that

$$
\begin{aligned}
& \beta d\left(x_{0},\left[S x_{0}\right]_{\alpha}\right)+\gamma d\left(x_{1},\left[T x_{1}\right]_{\alpha}\right) \\
& +\eta \frac{d\left(x_{0},\left[S x_{0}\right]_{\alpha}\right) d\left(x_{1},\left[T x_{1}\right]_{\alpha}\right)}{1+d\left(x_{0}, x_{1}\right)} \\
& \quad \in s\left(d\left(x_{1}, x_{2}\right)\right) .
\end{aligned}
$$

That is,

$$
\begin{aligned}
& d\left(x_{1}, x_{2}\right) \preceq \beta d\left(x_{0},\left[S x_{0}\right]_{\alpha}\right)+\gamma d\left(x_{1},\left[T x_{1}\right]_{\alpha}\right) \\
& +\eta \frac{d\left(x_{0},\left[S x_{0}\right]_{\alpha}\right) d\left(x_{1},\left[T x_{1}\right]_{\alpha}\right)}{1+d\left(x_{0}, x_{1}\right)} .
\end{aligned}
$$

By the meaning of $W_{x}\left([T y]_{\alpha}\right)$ and $W_{x}\left([S y]_{\alpha}\right)$ for $x, y \in X$, we get

$$
\begin{gathered}
d\left(x_{1}, x_{2}\right) \preceq \beta d\left(x_{0}, x_{1}\right)+\gamma d\left(x_{1}, x_{2}\right) \\
+\eta \frac{d\left(x_{0}, x_{1}\right) d\left(x_{1}, x_{2}\right)}{1+d\left(x_{0}, x_{1}\right)},
\end{gathered}
$$

which implies that

$$
\begin{aligned}
& \left|d\left(x_{1}, x_{2}\right)\right| \leq \beta\left|d\left(x_{0}, x_{1}\right)\right|+\gamma\left|d\left(x_{1}, x_{2}\right)\right| \\
& +\eta \frac{\left|d\left(x_{0}, x_{1}\right)\right|\left|d\left(x_{1}, x_{2}\right)\right|}{\left|1+d\left(x_{0}, x_{1}\right)\right|} .
\end{aligned}
$$

Thus

$$
\left|d\left(x_{1}, x_{2}\right)\right| \leq l\left|d\left(x_{0}, x_{1}\right)\right|
$$

where $l=\beta /(1-\gamma-\eta)<1$. Inductively, we can construct a sequence $\left\{x_{n}\right\}$ in $X$ such that, for $n=0,1,2, \ldots$,

$$
\left|d\left(x_{n}, x_{n+1}\right)\right| \leq l^{n}\left|d\left(x_{0}, x_{1}\right)\right|,
$$

with $l=\beta /(1-\gamma-\eta)<1$, for $x_{2 n+1} \in\left[S x_{2 n}\right]_{\alpha}$ and $x_{2 n+2} \epsilon$ $\left[T x_{2 n+1}\right]$. Now for $m>n$, we get

$$
\begin{aligned}
\left|d\left(x_{n}, x_{m}\right)\right| \leq & \left|d\left(x_{n}, x_{n+1}\right)\right|+\left|d\left(x_{n+1}, x_{n+2}\right)\right|+\cdots \\
& +\left|d\left(x_{m-1}, x_{m}\right)\right| \\
\leq & {\left[l^{n}+l^{n+1}+\cdots+l^{m-1}\right]\left|d\left(x_{0}, x_{1}\right)\right| } \\
\leq & {\left[\frac{l^{n}}{1-l}\right]\left|d\left(x_{0}, x_{1}\right)\right| }
\end{aligned}
$$

and so

$$
\left|d\left(x_{n}, x_{m}\right)\right| \leq \frac{l^{n}}{1-l}\left|d\left(x_{0}, x_{1}\right)\right| \longrightarrow 0 \quad \text { as } m, n \longrightarrow \infty .
$$

This implies that $\left\{x_{n}\right\}$ is a Cauchy sequence in $X$. Since $X$ is complete, there exists $v \in X$ such that $x_{n} \rightarrow v$ as $n \rightarrow \infty$. We now show that $v \in[T v]_{\alpha}$ and $v \in[S v]_{\alpha}$. From (43), we get

$$
\begin{aligned}
& \beta d\left(x_{2 n},\left[S x_{2 n}\right]_{\alpha}\right)+\gamma d\left(v,[T v]_{\alpha}\right) \\
& +\eta \frac{d\left(x_{2 n},\left[S x_{2 n}\right]_{\alpha}\right) d\left(v,[T v]_{\alpha}\right)}{1+d\left(x_{2 n}, v\right)} \\
& \in s\left(\left[S x_{2 n}\right]_{\alpha},[T v]_{\alpha}\right) .
\end{aligned}
$$

By Lemma 6 (iii), we have

$$
\begin{aligned}
& \beta d\left(x_{2 n},\left[S x_{2 n}\right]_{\alpha}\right)+\gamma d\left(v,[T v]_{\alpha}\right) \\
& +\eta \frac{d\left(x_{2 n},\left[S x_{2 n}\right]_{\alpha}\right) d\left(v,[T v]_{\alpha}\right)}{1+d\left(x_{2 n}, v\right)} \\
& \quad \in s\left(x_{2 n+1},[T v]_{\alpha}\right) .
\end{aligned}
$$

By definition there exists some $v_{n} \in[T v]_{\alpha}$ such that

$$
\begin{array}{r}
\beta d\left(x_{2 n},\left[S x_{2 n}\right]_{\alpha}\right)+\gamma d\left(v,[T v]_{\alpha}\right) \\
+\eta \frac{d\left(x_{2 n},\left[S x_{2 n}\right]_{\alpha}\right) d\left(v,[T v]_{\alpha}\right)}{1+d\left(x_{2 n}, v\right)}
\end{array}
$$

$$
\in s\left(d\left(x_{2 n+1}, v_{n}\right)\right) \text {. }
$$

That is,

$$
\begin{array}{r}
d\left(x_{2 n+1}, v_{n}\right) \preceq \beta d\left(x_{2 n},\left[S x_{2 n}\right]_{\alpha}\right)+\gamma d\left(v,[T v]_{\alpha}\right) \\
+\eta \frac{d\left(x_{2 n},\left[S x_{2 n}\right]_{\alpha}\right) d\left(v,[T v]_{\alpha}\right)}{1+d\left(x_{2 n}, v\right)} .
\end{array}
$$

By the meaning of $W_{x}\left([T y]_{\alpha}\right)$ and $W_{x}\left([S y]_{\alpha}\right)$ for $x, y \in X$, we get

$$
\begin{aligned}
& d\left(x_{2 n+1}, v_{n}\right) \preceq \beta d\left(x_{2 n}, x_{2 n+1}\right)+\gamma d\left(v, v_{n}\right) \\
& +\eta \frac{d\left(x_{2 n}, x_{2 n+1}\right) d\left(v, v_{n}\right)}{1+d\left(x_{2 n}, v\right)} .
\end{aligned}
$$

Now by using (58) and the triangular inequality, we get

$$
\begin{aligned}
d\left(v, v_{n}\right) \leq & d\left(v, x_{2 n+1}\right)+d\left(x_{2 n+1}, v_{n}\right) \\
\leq & d\left(v, x_{2 n+1}\right)+\beta d\left(x_{2 n}, x_{2 n+1}\right)+\gamma d\left(v, v_{n}\right) \\
& +\eta \frac{d\left(x_{2 n}, x_{2 n+1}\right) d\left(v, v_{n}\right)}{1+d\left(x_{2 n}, v\right)},
\end{aligned}
$$


which implies that

$$
\begin{aligned}
(1-\gamma)\left|d\left(v, v_{n}\right)\right| \leq & \left|d\left(v, x_{2 n+1}\right)\right| \\
& +\beta\left|d\left(x_{2 n}, x_{2 n+1}\right)\right| \\
& +\eta\left|\frac{d\left(x_{2 n}, x_{2 n+1}\right) d\left(v, v_{n}\right)}{1+d\left(x_{2 n}, v\right)}\right|, \\
\left|d\left(v, v_{n}\right)\right| \leq & \frac{1}{(1-\gamma)}\left|d\left(v, x_{2 n+1}\right)\right| \\
& +\frac{\beta}{(1-\gamma)}\left|d\left(x_{2 n}, x_{2 n+1}\right)\right| \\
& +\frac{\eta}{(1-\gamma)} \frac{\left|d\left(x_{2 n}, x_{2 n+1}\right)\right|\left|d\left(v, v_{n}\right)\right|}{\left|1+d\left(x_{2 n}, v\right)\right|} .
\end{aligned}
$$

By letting $n \rightarrow \infty$ in above inequality, we get

$$
\left|d\left(v, v_{n}\right)\right| \longrightarrow 0 \quad \text { as } n \longrightarrow \infty .
$$

By Lemma 2 [11], we have $v_{n} \rightarrow v$ as $n \rightarrow \infty$. Since $[T v]_{\alpha}$ is closed, so $v \in[T v]_{\alpha}$. Similarly, it follows that $v \in[S v]_{\alpha}$. Thus there exists some $v \in[S v]_{\alpha} \cap[T v]_{\alpha}$.

By setting $\eta=0$ and $k=\beta=\gamma$ in Theorem 19, we get the following corollary.

Corollary 20. Let $(X, d)$ be a complete complex valued metric space and let $S, T$ be fuzzy mappings from $X$ into $\mathscr{F}(X)$. Assume that there exists some $\alpha \in(0,1]$, such that, for each $x \in X,[S x]_{\alpha}$ and $[T x]_{\alpha}$ are nonempty closed bounded subsets of $X$; greatest lower bound of $W_{x}\left([T y]_{\alpha}\right), W_{x}\left([S y]_{\alpha}\right)$ exists in $\mathbb{C}$ for all $y \in X$ and

$$
k\left(d\left(x,[S x]_{\alpha}\right)+d\left(y,[T y]_{\alpha}\right)\right) \in s\left([S x]_{\alpha},[T y]_{\alpha}\right)
$$

for all $x, y \in X$ and $0 \leq k<1 / 2$. Then there exists some $v \in[S v]_{\alpha} \cap[T v]_{\alpha}$.

By setting $S=T$ in Theorem 19, we get the following corollary.

Corollary 21. Let $(X, d)$ be a complete complex valued metric space and let $T$ be fuzzy mapping from $X$ into $\mathscr{F}(X)$. Assume that there exists some $\alpha \in(0,1]$, such that, for each $x \in$ $X,[T x]_{\alpha}$ is nonempty closed bounded subset of $X$; greatest lower bound of $W_{x}\left([T y]_{\alpha}\right)$ exists in $\mathbb{C}$ for all $y \in X$ and

$$
\begin{gathered}
\beta d\left(x,[T x]_{\alpha}\right)+\gamma d\left(y,[T y]_{\alpha}\right) \\
+\eta \frac{d\left(x,[T x]_{\alpha}\right) d\left(y,[T y]_{\alpha}\right)}{1+d(x, y)} \\
\in s\left([T x]_{\alpha},[T y]_{\alpha}\right)
\end{gathered}
$$

for all $x, y \in X$ and nonnegative reals $\beta, \gamma$, and $\eta$ with $\beta+\gamma+\eta<$ 1. Then there exists some $v \in[T v]_{\alpha}$.

By Definition 11, one can have the following corollaries easily from Theorem 19.
Corollary 22. Let $(X, d)$ be a complete complex valued metric space and let $S, T$ be fuzzy mappings from $X$ into $\mathscr{F}(X)$ with g.l.b property such that, for each $x, y \in X$ and $\alpha \in(0,1],[S x]_{\alpha}$ and $[T y]_{\alpha}$ are nonempty closed bounded subsets of $X$ and

$$
\begin{gathered}
\beta d\left(x,[S x]_{\alpha}\right)+\gamma d\left(y,[T y]_{\alpha}\right) \\
+\eta \frac{d\left(x,[S x]_{\alpha}\right) d\left(y,[T y]_{\alpha}\right)}{1+d(x, y)} \\
\in s\left([S x]_{\alpha},[T y]_{\alpha}\right),
\end{gathered}
$$

for all $x, y \in X$ and nonnegative real numbers $\beta, \gamma$, and $\eta$ with $\beta+\gamma+\eta<1$. Then there exists some $v \in[S v]_{\alpha} \cap[T v]_{\alpha}$.

Remark 23. By Definition 11, one can have a host of corollaries of Kannan type contractive fuzzy mappings with g.l.b property easily from Theorem 19.

Corollary 24 (see[20]). Let $(X, d)$ be a complete complex valued metric space and let $F, G: X \rightarrow C B(X)$ be multivalued mappings with g.l.b property such that

$$
\begin{aligned}
& \beta d(x, F x)+\gamma d(y, G y) \\
& +\eta \frac{d(x, F x) d(y, G y)}{1+d(x, y)} \\
& \quad \in s(F x, G y)
\end{aligned}
$$

for all $x, y \in X$ and nonnegative real numbers $\beta, \gamma$, and $\eta$ with $\beta+\gamma+\eta<1$. Then there exists some $v \in F v \cap G v$.

Proof. Consider a pair of fuzzy mappings $S, T: X \rightarrow \mathscr{F}(X)$ defined by

$$
\begin{aligned}
& S(x)(t)= \begin{cases}\alpha, & t \in F x \\
0, & t \notin F x,\end{cases} \\
& T(x)(t)= \begin{cases}\alpha, & t \in G x \\
0, & t \notin G x,\end{cases}
\end{aligned}
$$

where $\alpha \in(0,1]$. Then

$$
[S x]_{\alpha}=\{t: S(x)(t) \geq \alpha\}=F x, \quad[T x]_{\alpha}=G x
$$

Thus, Theorem 19 can be applied to obtain $v \in X$ such that

$$
v \in[S v]_{\alpha} \cap[T v]_{\alpha}=F v \cap G v
$$

\subsection{Chatterjea Type Fuzzy Fixed Point Result}

Theorem 25. Let $(X, d)$ be a complete complex valued metric space and let $S, T$ be fuzzy mappings from $X$ into $\mathscr{F}(X)$. Assume that there exists some $\alpha \in(0,1]$, such that, for each $x \in X,[S x]_{\alpha}$, and $[T x]_{\alpha}$ are nonempty closed bounded subsets 
of $X$; greatest lower bound of $W_{x}\left([T y]_{\alpha}\right), W_{x}\left([S y]_{\alpha}\right)$ exists in $\mathbb{C}$ for all $y \in X$ and

$$
\begin{aligned}
& \operatorname{ad}\left(x,[T y]_{\alpha}\right)+b d\left(y,[S x]_{\alpha}\right) \\
& +c \frac{d\left(x,[T y]_{\alpha}\right) d\left(y,[S x]_{\alpha}\right)}{1+d(x, y)} \\
& \quad \in s\left([S x]_{\alpha},[T y]_{\alpha}\right),
\end{aligned}
$$

for all $x, y \in X$ and nonnegative reals $a, b$, and $c$ with $a+b+$ $c<1$. Then there exists some $w \in[S w]_{\alpha} \cap[T w]_{\alpha}$.

Proof. Let $x_{0}$ be an arbitrary point in $X$. By assumption, we can find $x_{1} \in\left[S x_{0}\right]_{\alpha}$. So, we have

$$
\begin{aligned}
& a d\left(x_{0},\left[T x_{1}\right]_{\alpha}\right)+b d\left(x_{1},\left[S x_{0}\right]_{\alpha}\right) \\
& +c \frac{d\left(x_{0},\left[T x_{1}\right]_{\alpha}\right) d\left(x_{1},\left[S x_{0}\right]_{\alpha}\right)}{1+d\left(x_{0}, x_{1}\right)} \\
& \quad \in s\left(\left[S x_{0}\right]_{\alpha},\left[T x_{1}\right]_{\alpha}\right) .
\end{aligned}
$$

By Lemma 6(iii), we have

$$
\begin{aligned}
& a d\left(x_{0},\left[T x_{1}\right]_{\alpha}\right)+b d\left(x_{1},\left[S x_{0}\right]_{\alpha}\right) \\
& +c \frac{d\left(x_{0},\left[T x_{1}\right]_{\alpha}\right) d\left(x_{1},\left[S x_{0}\right]_{\alpha}\right)}{1+d\left(x_{0}, x_{1}\right)} \\
& \in s\left(x_{1},\left[T x_{1}\right]_{\alpha}\right) .
\end{aligned}
$$

By definition there exists some $x_{2} \in\left[T x_{1}\right]_{\alpha}$, such that

$$
\begin{aligned}
& \operatorname{ad}\left(x_{0},\left[T x_{1}\right]_{\alpha}\right)+b d\left(x_{1},\left[S x_{0}\right]_{\alpha}\right) \\
& +c \frac{d\left(x_{0},\left[T x_{1}\right]_{\alpha}\right) d\left(x_{1},\left[S x_{0}\right]_{\alpha}\right)}{1+d\left(x_{0}, x_{1}\right)} \\
& \in s\left(d\left(x_{1}, x_{2}\right)\right) .
\end{aligned}
$$

That is,

$$
\begin{aligned}
d\left(x_{1}, x_{2}\right) \leq & a d\left(x_{0},\left[T x_{1}\right]_{\alpha}\right)+b d\left(x_{1},\left[S x_{0}\right]_{\alpha}\right) \\
& +c \frac{d\left(x_{0},\left[T x_{1}\right]_{\alpha}\right) d\left(x_{1},\left[S x_{0}\right]_{\alpha}\right)}{1+d\left(x_{0}, x_{1}\right)} .
\end{aligned}
$$

By the meaning of $W_{x}\left([T y]_{\alpha}\right)$ and $W_{x}\left([S y]_{\alpha}\right)$ for $x, y \in X$, we get

$$
\begin{aligned}
d\left(x_{1}, x_{2}\right) \leq & a d\left(x_{0}, x_{2}\right)+b d\left(x_{1}, x_{1}\right) \\
& +c \frac{d\left(x_{0}, x_{2}\right) d\left(x_{1}, x_{1}\right)}{1+d\left(x_{0}, x_{1}\right)},
\end{aligned}
$$

which implies that

$$
\left|d\left(x_{1}, x_{2}\right)\right| \leq \frac{a}{1-a}\left|d\left(x_{0}, x_{1}\right)\right| .
$$

Similarly from (69), we have

$$
\begin{aligned}
& \operatorname{ad}\left(x_{2},\left[T x_{1}\right]_{\alpha}\right)+b d\left(x_{1},\left[S x_{2}\right]_{\alpha}\right) \\
& +c \frac{d\left(x_{2},\left[T x_{1}\right]_{\alpha}\right) d\left(x_{1},\left[S x_{2}\right]_{\alpha}\right)}{1+d\left(x_{1}, x_{2}\right)} \\
& \in s\left(\left[T x_{1}\right]_{\alpha},\left[S x_{2}\right]_{\alpha}\right) .
\end{aligned}
$$

By Lemma 6(iii), we have

$$
\begin{aligned}
& a d\left(x_{2},\left[T x_{1}\right]_{\alpha}\right)+b d\left(x_{1},\left[S x_{2}\right]_{\alpha}\right) \\
& +c \frac{d\left(x_{2},\left[T x_{1}\right]_{\alpha}\right) d\left(x_{1},\left[S x_{2}\right]_{\alpha}\right)}{1+d\left(x_{1}, x_{2}\right)} \\
& \in s\left(x_{2},\left[S x_{2}\right]_{\alpha}\right) .
\end{aligned}
$$

By definition there exists some $x_{3} \in\left[S x_{2}\right]_{\alpha}$, such that

$$
\begin{aligned}
& a d\left(x_{2},\left[T x_{1}\right]_{\alpha}\right)+b d\left(x_{1},\left[S x_{2}\right]_{\alpha}\right) \\
& +c \frac{d\left(x_{2},\left[T x_{1}\right]_{\alpha}\right) d\left(x_{1},\left[S x_{2}\right]_{\alpha}\right)}{1+d\left(x_{1}, x_{2}\right)} \\
& \quad \in s\left(d\left(x_{2}, x_{3}\right)\right) .
\end{aligned}
$$

That is,

$$
\begin{array}{r}
d\left(x_{2}, x_{3}\right) \leq \\
\quad a d\left(x_{2},\left[T x_{1}\right]_{\alpha}\right)+b d\left(x_{1},\left[S x_{2}\right]_{\alpha}\right) \\
+c \frac{d\left(x_{2},\left[T x_{1}\right]_{\alpha}\right) d\left(x_{1},\left[S x_{2}\right]_{\alpha}\right)}{1+d\left(x_{1}, x_{2}\right)} .
\end{array}
$$

By the meaning of $W_{x}\left([T y]_{\alpha}\right)$ and $W_{x}\left([S y]_{\alpha}\right)$ for $x, y \in X$, we get

$$
\begin{array}{r}
d\left(x_{2}, x_{3}\right) \leq a d\left(x_{2}, x_{2}\right)+b d\left(x_{1}, x_{3}\right) \\
+c \frac{d\left(x_{2}, x_{2}\right) d\left(x_{1}, x_{3}\right)}{1+d\left(x_{1}, x_{2}\right)},
\end{array}
$$

which implies that

$$
\left|d\left(x_{2}, x_{3}\right)\right| \leq \frac{b}{1-b}\left|d\left(x_{1}, x_{2}\right)\right| .
$$

Inductively, we can construct a sequence $\left\{x_{n}\right\}$ in $X$ such that, for $n=0,1,2, \ldots$,

$$
\left|d\left(x_{n}, x_{n+1}\right)\right| \leq q^{n}\left|d\left(x_{0}, x_{1}\right)\right|,
$$

with $q=\max \{a /(1-a), b /(1-b)\}<1, x_{2 n+1} \in\left[S x_{2 n}\right]_{\alpha}$, and $x_{2 n+2} \in\left[T x_{2 n+1}\right]_{\alpha}$. Now for $m>n$, we get

$$
\begin{aligned}
\left|d\left(x_{n}, x_{m}\right)\right| \leq & \left|d\left(x_{n}, x_{n+1}\right)\right|+\left|d\left(x_{n+1}, x_{n+2}\right)\right| \\
& +\cdots+\left|d\left(x_{m-1}, x_{m}\right)\right| \\
\leq & {\left[q^{n}+q^{n+1}+\cdots+q^{m-1}\right]\left|d\left(x_{0}, x_{1}\right)\right| } \\
= & {\left[\frac{q^{n}}{1-q}\right]\left|d\left(x_{0}, x_{1}\right)\right|, }
\end{aligned}
$$


and so

$$
\left|d\left(x_{n}, x_{m}\right)\right| \leq \frac{q^{n}}{1-q}\left|d\left(x_{0}, x_{1}\right)\right| \longrightarrow 0 \quad \text { as } m, n \longrightarrow \infty .
$$

This implies that $\left\{x_{n}\right\}$ is a Cauchy sequence in $X$. Since $X$ is complete, there exists $w \in X$ such that $x_{n} \rightarrow w$ as $n \rightarrow \infty$. We now show that $w \in[T w]_{\alpha}$ and $w \in[S w]_{\alpha}$. From (69), we get

$$
\begin{aligned}
& a d\left(x_{2 n},[T w]_{\alpha}\right)+b d\left(w,\left[S x_{2 n}\right]_{\alpha}\right) \\
& +c \frac{d\left(x_{2 n},[T w]_{\alpha}\right) d\left(w,\left[S x_{2 n}\right]_{\alpha}\right)}{1+d\left(x_{2 n}, w\right)} \\
& \quad \in s\left(\left[S x_{2 n}\right]_{\alpha},[T w]_{\alpha}\right) .
\end{aligned}
$$

By Lemma 6(iii), we have

$$
\begin{aligned}
& a d\left(x_{2 n},[T w]_{\alpha}\right)+b d\left(w,\left[S x_{2 n}\right]_{\alpha}\right) \\
& +c \frac{d\left(x_{2 n},[T w]_{\alpha}\right) d\left(w,\left[S x_{2 n}\right]_{\alpha}\right)}{1+d\left(x_{2 n}, w\right)} \\
& \quad \in s\left(x_{2 n+1},[T w]_{\alpha}\right) .
\end{aligned}
$$

By definition there exists some $w_{n} \in[T w]_{\alpha}$, such that

$$
\begin{aligned}
& a d\left(x_{2 n},[T w]_{\alpha}\right)+b d\left(w,\left[S x_{2 n}\right]_{\alpha}\right) \\
& +c \frac{d\left(x_{2 n},[T w]_{\alpha}\right) d\left(w,\left[S x_{2 n}\right]_{\alpha}\right)}{1+d\left(x_{2 n}, w\right)} \\
& \quad \in s\left(x_{2 n+1},[T w]_{\alpha}\right) \in s\left(d\left(x_{2 n+1}, w_{n}\right)\right) .
\end{aligned}
$$

That is,

$$
\begin{aligned}
d\left(x_{2 n+1}, w_{n}\right) \leq & a d\left(x_{2 n},[T w]_{\alpha}\right)+b d\left(w,\left[S x_{2 n}\right]_{\alpha}\right) \\
& +c \frac{d\left(x_{2 n},[T w]_{\alpha}\right) d\left(w,\left[S x_{2 n}\right]_{\alpha}\right)}{1+d\left(x_{2 n}, w\right)} .
\end{aligned}
$$

By the meaning of $W_{x}\left([T y]_{\alpha}\right)$ and $W_{x}\left([S y]_{\alpha}\right)$ for $x, y \in X$, we get

$$
\begin{aligned}
d\left(x_{2 n+1}, v_{n}\right) \leq & a d\left(x_{2 n}, w_{n}\right)+b d\left(w, x_{2 n+1}\right) \\
& +c \frac{d\left(x_{2 n}, w_{n}\right) d\left(w, x_{2 n+1}\right)}{1+d\left(x_{2 n}, w\right)} .
\end{aligned}
$$

Now by using the triangular inequality, we get

$$
\begin{aligned}
d\left(x_{2 n+1}, w_{n}\right) \leq & a d\left(x_{2 n}, x_{2 n+1}\right) \\
& +a d\left(x_{2 n+1}, w_{n}\right)+b d\left(w, x_{2 n+1}\right) \\
& +c \frac{d\left(x_{2 n}, w_{n}\right) d\left(w, x_{2 n+1}\right)}{1+d\left(x_{2 n}, w\right)},
\end{aligned}
$$

and it follows that

$$
\begin{aligned}
d\left(x_{2 n+1}, w_{n}\right) \leq & \frac{a}{1-a} d\left(x_{2 n}, x_{2 n+1}\right)+\frac{b}{1-a} d\left(w, x_{2 n+1}\right) \\
& +\frac{c}{1-a} \frac{d\left(x_{2 n}, w_{n}\right) d\left(w, x_{2 n+1}\right)}{1+d\left(x_{2 n}, w\right)} .
\end{aligned}
$$

By using again triangular inequality, we get

$$
\begin{aligned}
d\left(w, w_{n}\right) \leq & d\left(w, x_{2 n+1}\right)+d\left(x_{2 n+1}, w_{n}\right) \\
\leq & d\left(w, x_{2 n+1}\right)+\frac{a}{1-a} d\left(x_{2 n}, x_{2 n+1}\right) \\
& +\frac{b}{1-a} d\left(w, x_{2 n+1}\right) \\
& +\frac{c}{1-a} \frac{d\left(x_{2 n}, w_{n}\right) d\left(w, x_{2 n+1}\right)}{1+d\left(x_{2 n}, w\right)}
\end{aligned}
$$

and it follows that

$$
\begin{aligned}
\left|d\left(w, w_{n}\right)\right| \leq & \left|d\left(w, x_{2 n+1}\right)\right|+\frac{a}{1-a}\left|d\left(x_{2 n}, x_{2 n+1}\right)\right| \\
& +\frac{b}{1-a}\left|d\left(w, x_{2 n+1}\right)\right| \\
& +\frac{c}{1-a} \frac{\left|d\left(x_{2 n}, w_{n}\right)\right|\left|d\left(w, x_{2 n+1}\right)\right|}{\left|1+d\left(x_{2 n}, w\right)\right|} .
\end{aligned}
$$

By letting $n \rightarrow \infty$ in above inequality, we get $\left|d\left(w, w_{n}\right)\right| \rightarrow 0$ as $n \rightarrow \infty$. By Lemma 2 [11], we have $w_{n} \rightarrow w$ as $n \rightarrow \infty$. Since $[T w]_{\alpha}$ is closed, so $w \in[T w]_{\alpha}$. Similarly, it follows that $w \in[S w]_{\alpha}$. Thus there exists some $w \in[S w]_{\alpha} \cap[T w]_{\alpha}$.

Corollary 26. Let $(X, d)$ be a complete complex valued metric space and let $S, T$ be fuzzy mappings from $X$ into $\mathscr{F}(X)$. Assume that there exists some $\alpha \in(0,1]$, such that, for each $x \in X,[S x]_{\alpha}$ and $[T x]_{\alpha}$ are nonempty closed bounded subsets of $X$; greatest lower bound of $W_{x}\left([T y]_{\alpha}\right), W_{x}\left([S y]_{\alpha}\right)$ exists in $\mathbb{C}$ for all $y \in X$ and

$$
h\left(d\left(x,[T y]_{\alpha}\right)+d\left(y,[S x]_{\alpha}\right)\right) \in s\left([S x]_{\alpha},[T y]_{\alpha}\right),
$$

for all $x, y \in X$ and $0 \leq h<1 / 2$. Then there exists some $w \in[S w]_{\alpha} \cap[T w]_{\alpha}$.

By taking $S=T$ in Theorem 25, we get the following corollary.

Corollary 27. Let $(X, d)$ be a complete complex valued metric space and let $T$ be fuzzy mapping from $X$ into $\mathscr{F}(X)$. Assume that there exists some $\alpha \in(0,1]$ such that, for each $x \in$ $X,[T x]_{\alpha}$ is nonempty closed bounded subset of $X$; greatest lower bound of $W_{x}\left([T y]_{\alpha}\right)$ exists in $\mathbb{C}$ for all $y \in X$ and

$$
\begin{gathered}
a d\left(x,[T y]_{\alpha}\right)+b d\left(y,[T x]_{\alpha}\right) \\
+c \frac{d\left(x,[T y]_{\alpha}\right) d\left(y,[T x]_{\alpha}\right)}{1+d(x, y)} \\
\quad \in s\left([T x]_{\alpha},[T y]_{\alpha}\right),
\end{gathered}
$$


for all $x, y \in X$ and nonnegative reals $a, b$, and $c$ with $a+b+c<$ 1. Then there exists some $w \in[T w]_{\alpha}$.

Corollary 28. Let $(X, d)$ be a complete complex valued metric space and let $S, T$ be fuzzy mappings from $X$ into $\mathscr{F}(X)$ with g.l.b property such that, for each $x, y \in X$ and $\alpha \in(0,1],[S x]_{\alpha}$ and $[T y]_{\alpha}$ are nonempty closed bounded subsets of $X$ and

$$
\begin{aligned}
& \operatorname{ad}\left(x,[T y]_{\alpha}\right)+b d\left(y,[S x]_{\alpha}\right) \\
& +c \frac{d\left(x,[T y]_{\alpha}\right) d\left(y,[S x]_{\alpha}\right)}{1+d(x, y)} \\
& \in s\left([S x]_{\alpha},[T y]_{\alpha}\right),
\end{aligned}
$$

for all $x, y \in X$ and nonnegative reals $a, b$, and $c$ with $a+b+c<$ 1. Then there exists some $w \in[S w]_{\alpha} \cap[T w]_{\alpha}$.

Remark 29. By Definition 11, one can have a host of corollaries of Chatterjea type contractive fuzzy mappings with g.l.b property easily from Theorem 25 .

Corollary 30 (see [20]). Let $(X, d)$ be a complete complex valued metric space and let $F, G: X \rightarrow C B(X)$ be multivalued mappings with g.l.b property such that

$$
a d(x, G y)+b d(y, F x)+c \frac{d(x, G y) d(y, F x)}{1+d(x, y)} \in s(F x, G y),
$$

for all $x, y \in X$ and nonnegative reals $a, b$, and $c$ with $a+b+c<$ 1. Then there exists some $w \in F w \cap G w$.

Proof. Consider a pair of fuzzy mappings $S, T: X \rightarrow \mathscr{F}(X)$ defined by

$$
\begin{aligned}
& S(x)(t)= \begin{cases}\alpha, & t \in F x \\
0, & t \notin F x,\end{cases} \\
& T(x)(t)= \begin{cases}\alpha, & t \in G x \\
0, & t \notin G x,\end{cases}
\end{aligned}
$$

where $\alpha \in(0,1]$. Then

$$
[S x]_{\alpha}=\{t: S(x)(t) \geq \alpha\}=F x, \quad[T x]_{\alpha}=G x .
$$

Thus, Theorem 25 can be applied to obtain $w \in X$ such that

$$
w \in[S w]_{\alpha} \cap[T w]_{\alpha}=F w \cap G w .
$$

\section{Remark 31. Consider the following.}

(i) By setting $\zeta, \kappa$, and $\varsigma$ in Corollary $18, \beta, \gamma$, and $\eta$ in Corollary 24, and $a, b$, and $c$ in Corollary 30 with different combinations, one can get corresponding results in $[19,20]$ as corollaries.

(ii) By Remark 7 and Corollaries 18, 24, and 30, one can easily get the results of $[13,18-21]$.
Example 32. Let $X=[0,1]$ and let $\mathbb{C}$ be the set of complex numbers; define $d: X \times X \rightarrow \mathbb{C}$ as follows:

$$
\begin{aligned}
d(x, y) & =|x-y| e^{i \theta}, \quad \text { where } \theta=\operatorname{Arg}(z), \\
z & =x+i y, \quad \text { and }|\cdot| \text { is modulus function. }
\end{aligned}
$$

Then $(X, d)$ is a complete complex valued metric space. Define a pair of mappings $S, T: X \rightarrow(X)$, for $\alpha \in(0,1]$ as follows.

For $x, y \in X$ with $x \leq y$, we have

$$
\begin{aligned}
& S(x)(t)= \begin{cases}\alpha & \text { if } 0 \leq t \leq \frac{x}{40} \\
\frac{\alpha}{2} & \text { if } \frac{x}{40}<t \leq \frac{x}{30} \\
\frac{\alpha}{3} & \text { if } \frac{x}{30}<t \leq \frac{x}{20} \\
\frac{\alpha}{5} & \text { if } \frac{x}{20}<t \leq 1,\end{cases} \\
& T(x)(t)= \begin{cases}\alpha & \text { if } 0 \leq t \leq \frac{x}{20} \\
\frac{\alpha}{3} & \text { if } \frac{x}{20}<t \leq \frac{x}{10} \\
\frac{\alpha}{4} & \text { if } \frac{x}{10}<t \leq \frac{x}{5} \\
\frac{\alpha}{7} & \text { if } \frac{x}{5}<t \leq 1,\end{cases}
\end{aligned}
$$

such that

$$
[T x]_{\alpha}=\left[0, \frac{x}{20}\right], \quad[S x]_{\alpha}=\left[0, \frac{x}{40}\right],
$$

and then

$$
\begin{aligned}
& W_{x}\left([T y]_{\alpha}\right)=\left\{d(x, u): u \in\left[0, \frac{y}{20}\right]\right\}, \\
& W_{y}\left([S x]_{\alpha}\right)=\left\{d(y, v): v \in\left[0, \frac{x}{40}\right]\right\} .
\end{aligned}
$$

Denote $d\left(x,[T x]_{\alpha}\right)$ and $d\left(x,[S x]_{\alpha}\right)$ by the greatest lower bounds of $W_{x}\left([T x]_{\alpha}\right)$ and $W_{x}\left([S x]_{\alpha}\right)$. Then

$$
\begin{aligned}
& d\left(x,[T y]_{\alpha}\right)(z)= \begin{cases}0 & \text { if } x<\frac{y}{20} \\
\left(x-\frac{y}{20}\right) e^{i \theta} & \text { if } x>\frac{y}{20}\end{cases} \\
& d\left(y,[S x]_{\alpha}\right)(z)=\left\{\left(y-\frac{x}{40}\right) e^{i \theta}, \quad \text { as } y>\frac{x}{40},\right.
\end{aligned}
$$

and also

$$
\begin{aligned}
& d\left(y,[T y]_{\alpha}\right)(z)=\left(\frac{19 y}{20}\right) e^{i \theta} \\
& d\left(x,[S x]_{\alpha}\right)(z)=\left(\frac{39 x}{40}\right) e^{i \theta} .
\end{aligned}
$$


Moreover, if $w_{y x} \in \mathbb{C}$ such that

$$
w_{y x}=\left|\frac{y}{20}-\frac{x}{40}\right| e^{\theta}
$$

then

$$
s\left([T y]_{\alpha},[S x]_{\alpha}\right)=\left\{w \in \mathbb{C}: w_{x y} \preceq w\right\} .
$$

For $x>y / 20$, we have

$$
\begin{aligned}
& \frac{d\left(y,[T y]_{\alpha}\right)+d\left(x,[S x]_{\alpha}\right)}{3}(z) \\
&=\frac{1}{3}\left(\frac{19 y}{20}+\frac{39 x}{40}\right) e^{i \theta} \\
&=\frac{1}{3}\left(y-\frac{y}{20}+x-\frac{x}{40}\right) e^{i \theta} \\
&=\frac{1}{3}\left(y-\frac{x}{40}+x-\frac{y}{20}\right) e^{i \theta} \\
&=\frac{1}{3}\left(y-\frac{x}{40}\right) e^{i \theta}+\left(x-\frac{y}{20}\right) e^{i \theta} \\
&=\frac{d\left(y,[S x]_{\alpha}\right)+d\left(x,[T y]_{\alpha}\right)}{3}(z) \\
&=\frac{1}{3}\left(\frac{6 y}{20}+\frac{13 y}{20}+\frac{6 x}{40}+\frac{33 x}{40}\right) e^{i \theta} \\
&=\frac{1}{3}\left(\frac{6 y}{20}+\frac{6 x}{40}\right) e^{i \theta}+\left(\frac{13 y}{20}+\frac{33 x}{40}\right) e^{i \theta} \\
&> \frac{1}{3}\left(\frac{6 y}{20}+\frac{6 x}{40}\right) e^{i \theta}=w_{x y}, \\
&=\left.\frac{2 y}{20}+\frac{2 x}{40}\right) e^{i \theta}>\left(\frac{y}{20}+\frac{x}{40}\right) e^{i \theta} \\
& \frac{y}{40}+(y)
\end{aligned}
$$

also as

$$
\frac{1}{2} d(x, y)=\frac{1}{2}|x-y| e^{i \theta} \geq\left|\frac{y}{20}-\frac{x}{40}\right| e^{i \theta} .
$$

It follows that, with $\zeta=\kappa=1 / 3, \varsigma \neq 0$, such that $\zeta+\kappa+\varsigma<1$, we have

$$
\begin{gathered}
\zeta d\left(x,[S x]_{\alpha}\right)+\kappa d\left(y,[T y]_{\alpha}\right) \\
+\varsigma \frac{d\left(x,[S x]_{\alpha}\right) d\left(y,[T y]_{\alpha}\right)}{1+d(x, y)} \\
\in s\left([S x]_{\alpha},[T y]_{\alpha}\right), \\
\zeta d\left(x,[T y]_{\alpha}\right)+\kappa d\left(y,[S x]_{\alpha}\right) \\
+\varsigma \frac{d\left(x,[T y]_{\alpha}\right) d\left(y,[S x]_{\alpha}\right)}{1+d(x, y)} \\
\in s\left([S x]_{\alpha},[T y]_{\alpha}\right),
\end{gathered}
$$

and for $\zeta=1 / 2$ with $\kappa \neq 0$ and $\varsigma \neq 0$, such that $\zeta+\kappa+\varsigma<1$, we have

$$
\begin{aligned}
& \zeta d(x, y) \\
& +\frac{\kappa d\left(x,[S x]_{\alpha}\right) d\left(y,[T y]_{\alpha}\right)+\varsigma d\left(y,[S x]_{\alpha}\right) d\left(x,[T y]_{\alpha}\right)}{1+d(x, y)} \\
& \quad \in s\left([S x]_{\alpha},[T y]_{\alpha}\right) .
\end{aligned}
$$

Hence $T$ and $S$ satisfy all the conditions of our main Theorem 12 to obtain $0 \in[S 0]_{\alpha} \cap[T 0]_{\alpha}$.

\section{Conflict of Interests}

The authors declare that there is no conflict of interests regarding the publication of this paper.

\section{Acknowledgments}

This paper was funded by the Deanship of Scientific Research (DSR), King Abdulaziz University, Jeddah. Therefore, the authors acknowledge with thanks DSR, KAU, for financial support.

\section{References}

[1] S. Heilpern, "Fuzzy mappings and fixed point theorem," Journal of Mathematical Analysis and Applications, vol. 83, no. 2, pp. 566-569, 1981.

[2] A. Azam and I. Beg, "Common fixed points of fuzzy maps," Mathematical and Computer Modelling, vol. 49, no. 7-8, pp. 13311336, 2009.

[3] A. Azam, M. Arshad, and P. Vetro, "On a pair of fuzzy $\varphi$ contractive mappings," Mathematical and Computer Modelling, vol. 52, no. 1-2, pp. 207-214, 2010.

[4] R. K. Bose and D. Sahani, "Fuzzy mappings and fixed point theorems," Fuzzy Sets and Systems, vol. 21, no. 1, pp. 53-58, 1987.

[5] S. S. Chang, Y. J. Cho, B. S. Lee, J. S. Jung, and S. M. Kang, "Coincidence point theorems and minimization theorems in fuzzy metric spaces," Fuzzy Sets and Systems, vol. 88, no. 1, pp. 119-127, 1997.

[6] Y. J. Cho and N. Petrot, "Existence theorems for fixed fuzzy points with closed $\alpha$-cut sets in complete metric spaces," Communications of the Korean Mathematical Society, vol. 26, no. 1, pp. 115-124, 2011.

[7] N. Hussain, S. Khaleghizadeh, P. Salimi, and A. A. N. Abdou, "A new approach to fixed point results in triangular intuitionistic fuzzy metric spaces," Abstract and Applied Analysis, vol. 2014, Article ID 690139, 16 pages, 2014.

[8] D. Qiu and L. Shu, "Supremum metric on the space of fuzzy sets and common fixed point theorems for fuzzy mappings," Information Sciences, vol. 178, no. 18, pp. 3595-3604, 2008.

[9] R. A. Rashwan and M. A. Ahmed, "Common fixed point theorems for fuzzy mappings," Archivum Mathematicum, vol. 38, no. 3, pp. 219-226, 2002.

[10] S. S. Zhang, "Fixed point theorems for fuzzy mappings. II," Applied Mathematics and Mechanics, vol. 7, no. 2, pp. 133-138, 1986. 
[11] A. Azam, B. Fisher, and M. Khan, "Common fixed point theorems in complex valued metric spaces," Numerical Functional Analysis and Optimization, vol. 32, no. 3, pp. 243-253, 2011.

[12] M. Abbas, M. Arshad, and A. Azam, "Fixed points of asymptotically regular mappings in complex-valued metric space," Georgian Mathematical Journal, vol. 20, no. 2, pp. 213-221, 2013.

[13] M. Abbas, B. Fisher, and T. Nazir, "Well-Posedness and periodic point property of mappings satisfying a rational inequality in an ordered complex valued metric space," Numerical Functional Analysis and Optimization, vol. 243, article 32, 2011.

[14] C. Klin-eam and C. Suanoom, "Some common fixed-point theorems for generalized-contractive-type mappings on complexvalued metric spaces," Abstract and Applied Analysis, vol. 2013, Article ID 604215, 6 pages, 2013.

[15] F. Rouzkard and M. Imdad, "Some common fixed point theorems on complex valued metric spaces," Computers \& Mathematics with Applications, vol. 64, no. 4, pp. 1866-1874, 2012.

[16] W. Sintunavarat and P. Kumam, "Generalized common fixed point theorems in complex valued metric spaces and applications," Journal of Inequalities and Applications, vol. 2012, article 84, 2012.

[17] K. Sitthikul and S. Saejung, "Some fixed point theorems in complex valued metric spaces," Fixed Point Theory and Applications, vol. 2012, article 189, 2012.

[18] A. Azam, "Fuzzy fixed points of fuzzy mappings via a rational inequality," Hacettepe Journal of Mathematics and Statistics, vol. 40, no. 3, pp. 421-431, 2011.

[19] J. Ahmad, C. Klin-Eam, and A. Azam, "Common fixed points for multivalued mappings in complex valued metric spaces with applications," Abstract and Applied Analysis, vol. 2013, Article ID 854965, 12 pages, 2013.

[20] A. Azam, J. Ahmad, and P. Kumam, "Common fixed point theorems for multi-valued mappings in complex-valued metric spaces," Journal of Inequalities and Applications, vol. 2013, article 578, 2013.

[21] S. B. Nadler Jr., "Multi-valued contraction mappings," Pacific Journal of Mathematics, vol. 30, pp. 475-488, 1969. 


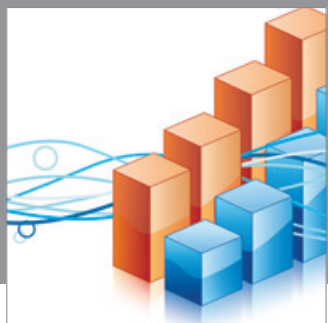

Advances in

Operations Research

mansans

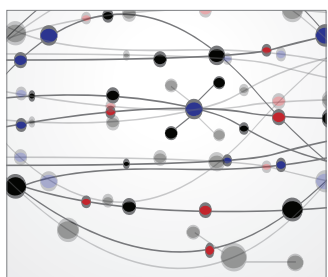

The Scientific World Journal
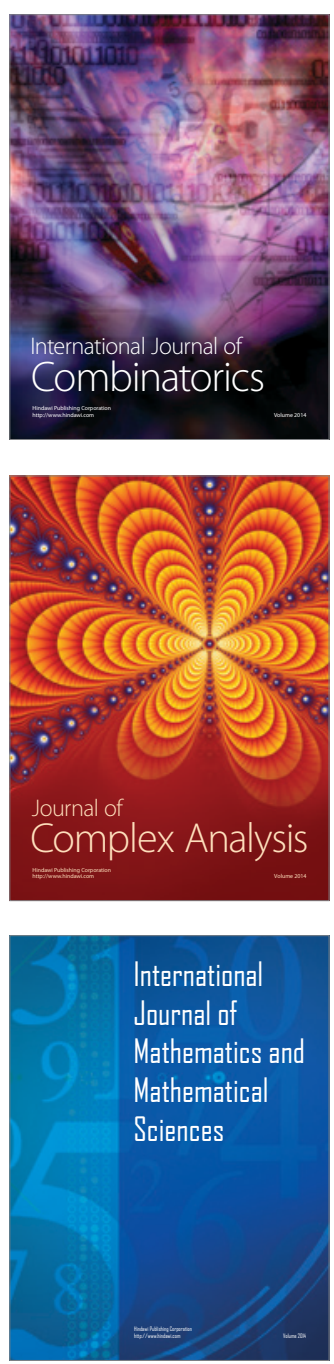
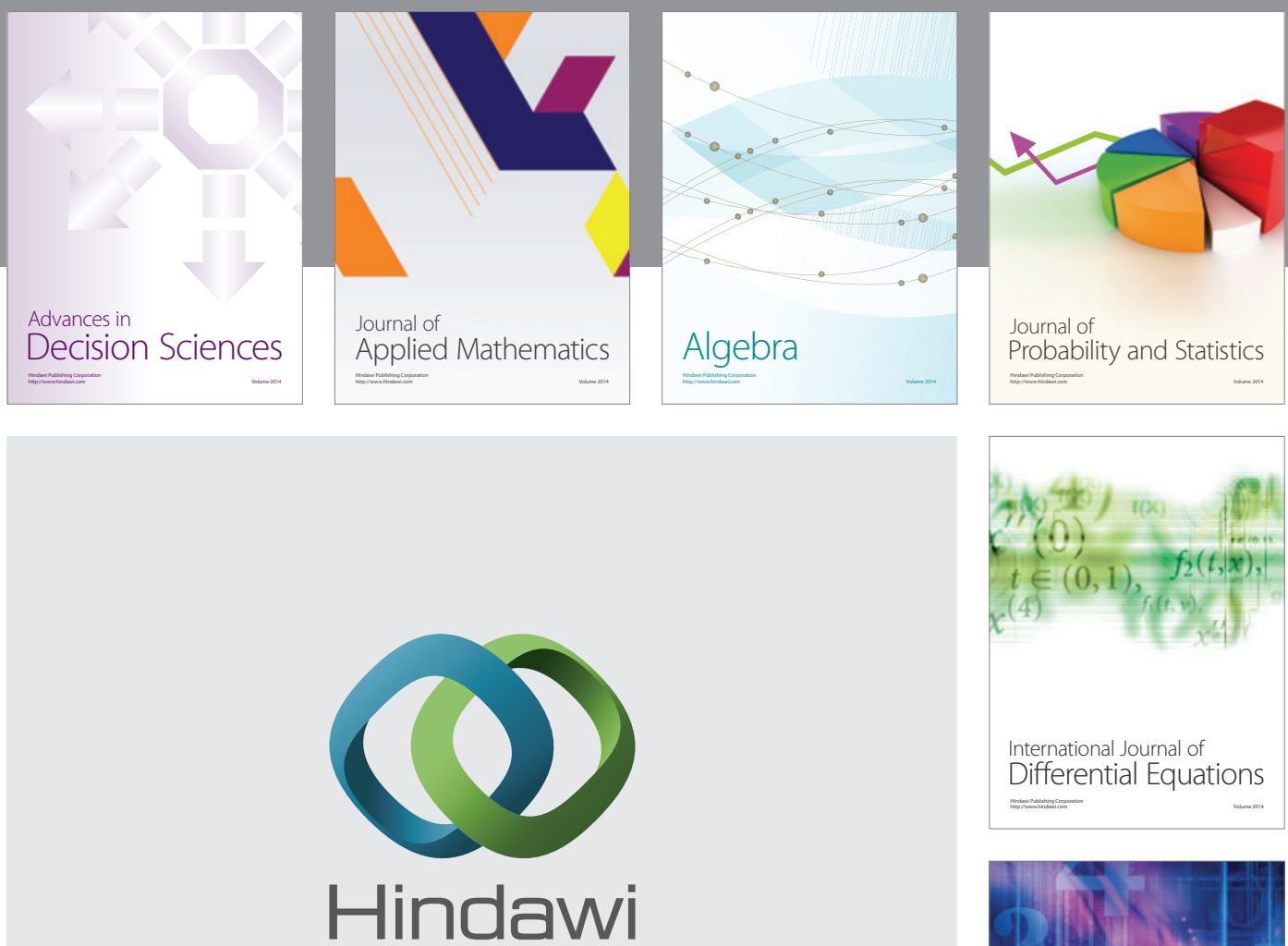

Submit your manuscripts at http://www.hindawi.com
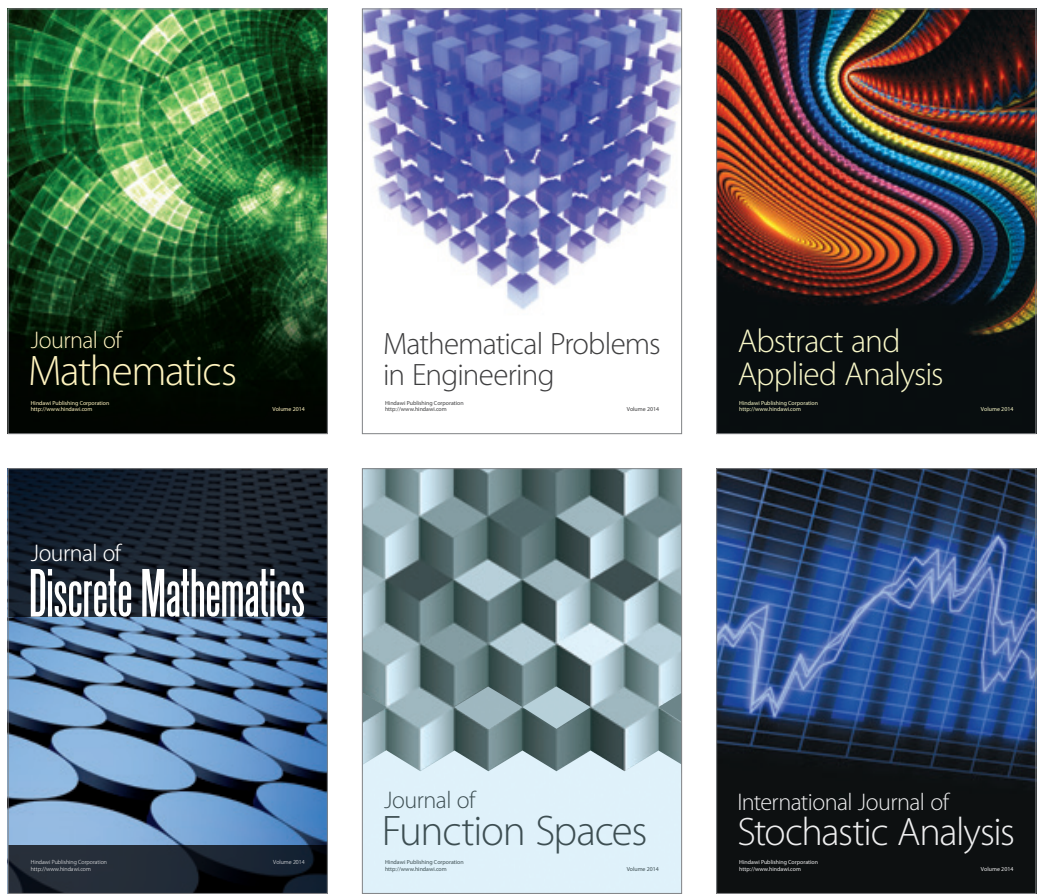

Journal of

Function Spaces

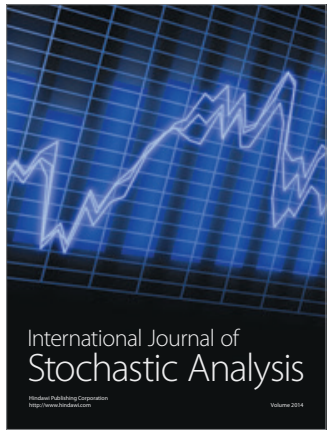

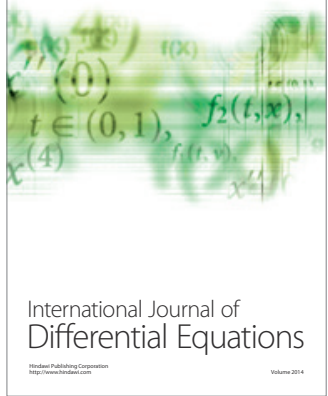
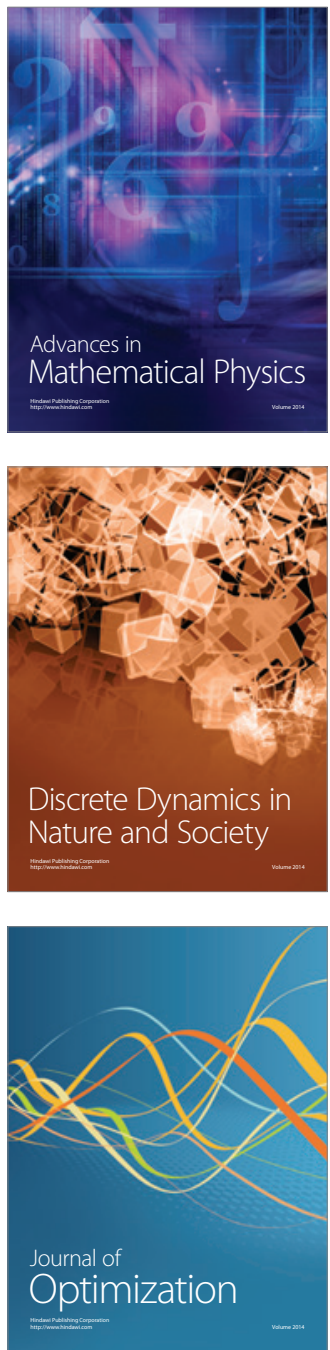